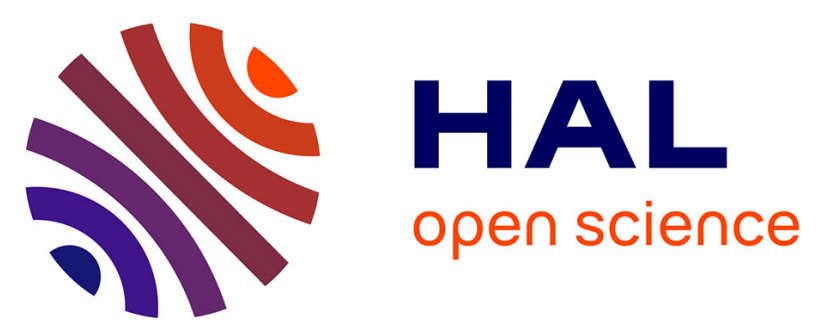

\title{
Aptitude à la coagulation du lait de vache. Influence de la race, des variants génétiques des lactoprotéines du lait, de l'alimentation et du numéro de lactation
}

Didier Macheboeuf, J-B. Coulon, P. d'Hour

\section{- To cite this version:}

Didier Macheboeuf, J-B. Coulon, P. d'Hour. Aptitude à la coagulation du lait de vache. Influence de la race, des variants génétiques des lactoprotéines du lait, de l'alimentation et du numéro de lactation. Productions Animales, 1993, 6 (5), pp.333-344. hal-00896066

\section{HAL Id: hal-00896066 https://hal.science/hal-00896066}

Submitted on 1 Jan 1993

HAL is a multi-disciplinary open access archive for the deposit and dissemination of scientific research documents, whether they are published or not. The documents may come from teaching and research institutions in France or abroad, or from public or private research centers.
L'archive ouverte pluridisciplinaire HAL, est destinée au dépôt et à la diffusion de documents scientifiques de niveau recherche, publiés ou non, émanant des établissements d'enseignement et de recherche français ou étrangers, des laboratoires publics ou privés. 
INRA Prod. Anim., 1993, 6 (5), 333 - 344.
D. MACHEBOEUF, J-B. COULON*, P. D'HOUR*

INRA Laboratoire de Recherches Fromagères

Route de Salers, 15000 Aurillac.

* INRA Laboratoire Adaptation des

Herbivores aux Milieux

Theix 63122 Saint-Genès Champanelle
Aptitude à la coagulation du lait de vache. Influence de la race, des variants génétiques des lactoprotéines du lait, de l'alimentation et du numéro de lactation.
L'aptitude du lait à la coagulation est un des facteurs déterminants de la quantité de fromage produite et de sa qualité. Elle dépend en partie de la composition chimique du lait, dont les principaux facteurs de variations ont été largement étudiés (Sutton 1989, Hoden et Coulon 1991). Elle dépend aussi de facteurs génétiques (race et/ou variants génétiques des protéines) (Grosclaude 1988, Aleandri et al 1990). Si l'on connait assez bien les relations entre les principaux critères de l'aptitude à la coagulation du lait (temps de coagulation, fermeté du gel et temps de raffermissement) et sa composition chimique (Remeuf et al 1989, Vertès et al 1989), l'effet spécifique des facteurs de production (en particulier de l'alimentation) et leurs interactions avec les facteurs génétiques ou saisonniers n'a fait l'objet que de peu de travaux (Grandison et al 1985a, Vertès et Hoden 1989, Laurent et al 1992).

L'objectif de cette étude, conduite au cours de 2 années successives, a été de préciser les variations de composition chimique et d'apti-

\section{Résumé}

Cent trente sept vaches laitières de race Pie-Noir (41), Montbéliarde (42) ou Tarentaise (54), en première ou deuxième lactation, ont recu au cours de l'hiver deux niveaux d'alimentation énergétique (haut $: H$ et bas : $B$ ), et ont été ensuite alimentées de manière identique au pâturage. Des mesures individuelles de la composition chimique du lait et de son aptitude à la coagulation ont été réalisées 3 fois pendant l'hiver et 2 fois au pâturage. Chez les Pie-Noir, les taux de caséines et de calcium et l'aptitude à la coagulation (temps de raffermissement et fermeté du gel) ont été inférieurs $(\mathrm{P}<0,01)$ à ceux mesurés chez les vaches Montbéliardes et Tarentaises. Ces écarts disparaissent pratiquement lorsque l'on tient compte de la répartition des différents variants de la caséine kappa et de la teneur en caséines du lait. Les laits de type kappa BB ont présenté une aptitude à la coagulation supérieure de 20 à $50 \%$ selon les paramètres à ceux de type $\mathrm{AA}$. Dans les 3 races, le lait des animaux du lot $\mathrm{H}$ ont présenté des taux de caséines supérieurs de $1,4 \mathrm{~g} / \mathrm{l}$ à ceux des lots $\mathrm{B}$, ce qui a entraîné une amélioration significative du temps de raffermissement, de la fermeté du gel et du rendement fromager. La mise à l'herbe s'est accompagnée d'une augmentation de 0,02 unité du $\mathrm{pH}$ du lait et d'une amélioration de son aptitude à la coagulation. Ces modifications ne semblent pas pouvoir être totalement expliquées par l'augmentation parallèle du taux de caséines du lait. L'aptitude du lait à la coagulation, mesurée chez les mêmes animaux au cours de leur 2 premières lactations, semble supérieure en deuxième lactation. tude à la coagulation du lait issu d'animaux de 3 races différentes, en fonction du niveau des apports alimentaires hivernaux et lors de la mise à l'herbe. Par ailleurs, les données obtenues sur les vaches de cet essai qui avaient été conduites les 2 années consécutives dans les mêmes conditions d'alimentation (la première année comme primipares, la seconde comme multipares) ont été traitées pour analyser l'effet de l'âge sur les caractéristiques rhéologiques du lait.

\section{1 / Conditions expérimentales}

\section{1 / Dispositif expérimental}

Cent trente sept vaches laitières (41 PieNoir (PN), 42 Montbéliardes (MO) et 54 Tarentaises (TA)) vêlant entre le 22 novembre et le 8 février ont reçu une alimentation énergétique à 2 niveaux (haut : $\mathrm{H}$ et bas : B) au cours de 2 hivers successifs ( 59 vaches primipares la première année, 32 vaches primipares et 46 vaches en 2ème lactation la seconde année).

Ces animaux ont été alimentés pendant toute la période hivernale (1er novembre au 8 mai) avec une ration à base de foin de prairie permanente offert à volonté $(0,71$ UFL, $65 \mathrm{~g}$ PDIN et $77 \mathrm{~g}$ PDIE par kg MS), complémentée à l'aide d'un aliment concentré équilibré $(1,07$ UFL, $126 \mathrm{~g}$ PDIN et $115 \mathrm{~g}$ PDIE par $\mathrm{kg}$ MS) composé essentiellement de céréales (44\%), de pulpes de betteraves $(38 \%)$ et de tourteau de soja $(9 \%)$ et distribué 2 fois par jour. La complémentation était déterminée pour toute la période hivernale, à partir de la production initiale (PI, production moyenne des 4ème, 5ème et 6ème jours de lactation) d'après les relations proposées par Faverdin et al (1987) et en tenant compte, au-delà du pic de production, d'une décroissance mensuelle de la production de $94 \%$ pour les primipares et de $89 \%$ pour les multipares. Les animaux des lots $\mathrm{H}$ étaient 
complémentés selon les recommandations INRA. Les animaux des lots B recevaient, pour une même production laitière estimée, $3 \mathrm{~kg} / \mathrm{j}$ d'aliment concentré en moins, à partir du 11 ème jour de lactation. Dans le lot $B$, la substitution de 0,5 à $1 \mathrm{~kg} / \mathrm{j}$ de tourteau de soja à la même quantité de concentré équilibré a permis d'obtenir des apports azotés identiques dans les 2 lots, et couvrant largement les besoins.

Au pâturage (à partir du 8 mai), tous les animaux ont été conduits ensemble, en pâturage tournant, et complémentés en aliment concentré lorsque leur production dépassait $17 \mathrm{~kg} / \mathrm{j}$ au printemps et $12 \mathrm{~kg} / \mathrm{j}$ à l'automne pour les primipares (respectivement 20 et $15 \mathrm{~kg} / \mathrm{j}$ pour les multipares). Durant toute la lactation, les animaux étaient traits 2 fois par jour, à $6 \mathrm{~h}$ et à $16 \mathrm{~h}$.

\section{2 / Mesures et analyses}

Des échantillons de lait ont été recueillis sur les 137 vaches, à la traite du matin, 3 fois au cours de l'hiver ( 1 : février, 2 : mars et
3 : avril) et 2 fois au cours de la période de pâturage ( 4 : juin et 5 : juillet). Sur chacun de ces échantillons, des mesures de composition chimique et d'aptitude à la coagulation ont été réalisées. Les teneurs en lactose, en calcium, en matières grasses et en matières azotées totales ont été mesurées, ainsi que les différentes fractions azotées du lait (caséines, protéines solubles et urée). Par ailleurs une numération cellulaire du lait a été effectuée ainsi qu'un contrôle bactériologique (flore totale et contamination butyrique)

Le $\mathrm{pH}$ du lait a été mesuré juste après la traite. Les mesures rhéologiques ont été effectuées à l'aide d'un Formagraph selon la méthode proposée par Mc Mahon et Brown (1982)(cf encadré). Les mesures ont été réalisées au $\mathrm{pH}$ initial du lait ( $\mathrm{pHi})$, puis après standardisation du $\mathrm{pH}$ à une valeur de $6,60(\mathrm{pHs})$, par ajout de quelques gouttes d'acide lactique à $10 \%$. Toutes les mesures ont été réalisées en double. Les paramètres rhéologiques mesurés ont été le temps de coagulation ( $\mathrm{Ri}$ et $\mathrm{Rs}$ ), le temps de raf-

Mesure de l'aptitude à la coagulation du lait

(d'après Brulé et Lenoir 1987 et Vertès 1989)

La transformation du lait en fromage comporte en général quatre étapes :

La coagulation : modifications physico-chimiques des micelles de caséine sous l'action d'enzymes protéolytiques et (ou) d'acide lactique. Elles entraînent la formation d'un réseau protéique appelé coagulum ou gel.

L'égouttage : séparation du lactosérum, après rupture mécanique du coagulum, par moulage et, dans certains cas, pression. II conduit à l'obtention du caillé.

Le salage : incorporation de sel par dépôt en surface ou dans la masse, ou immersion en saumure.

L'affinage : transformations biochimiques des constituants du caillé sous l'action d'enzymes, pour la plupart d'origine microbienne.

Selon les paramètres technologiques mis en oeuvre au niveau de ces quatre étapes on peut obtenir une très grande variété de fromages.

Les caractéristiques de la première étape peuvent être appréciées à l'aide d'un Formagraph. Cet appareil est un viscosimètre à mouvement de translation oscillatoire permettant d'analyser l'aptitude à la coagulation de 10 échantillons de lait simultanément. La rampe de réception des échantillons est constituée de 10 cuves contenant chacune $10 \mathrm{ml}$ de lait emprésuré à raison de $20 \mathrm{ml}$ de présure diluée 50 fois par litre de lait et maintenues à $35^{\circ} \mathrm{C}$. Elles sont soumises à un mouvement oscillatoire de $7 \mathrm{~mm}$ d'amplitude et de $30 \mathrm{~s}$ de fréquence. A chaque cuve est associé un pendule constitué d'un axe horizontal muni d'un miroir et aux extrémités duquel sont fixés 2 éléments verticaux : un plongeur qui va tremper dans la cuve et un contrepoids. Tant que le lait ne coagule pas , le pendule reste immobile. Par contre, au fur et à mesure de l'augmentation de la consistance du caillé, le pendule est de plus en plus entraîné par les mouvements latéraux de la cuve. Le miroir réféchit sur un papier photosensible se déroulant à la vitesse de $2 \mathrm{~mm} / \mathrm{min}$ des flashs lumineux émis à chaque fois que la vitesse de déplacement de la cuve s'annule, c'est-à-dire lorsque la cuve arrive à une extrémité de son parcours latéral.

Le suivi rhéologique de la coagulation du lait se traduit par une courbe du type ci-contre. Les paramètres caractéristiques de la courbe sont les suivants :

$\mathbf{R}$ : représente le temps de coagulation ou temps depuis l'emprésurage, à partir duquel le Formagraph détecte un changement de comportement rhéologique.

K20 : c'est le temps nécessaire, après la coagulation pour que le caillé atteigne une consistance donnée, matérialisée par une largeur de $20 \mathrm{~mm}$ entre les branches du graphe.

A30 représente l'écartement des branches $30 \mathrm{~min}$ après l'emprésurage. On mesure également l'écartement après un délai égal à 2 fois le temps de coagulation (A2R) et l'écart maximal (AMax).

Compte tenu de la sensibilité de ces paramètres aux variations du $\mathrm{pH}$ du lait, les mesures sont généralement réalisées d'une part au $\mathrm{pH}$ natif du lait $(\mathrm{pH}$ initial) et d'autre part après standardisation du $\mathrm{pH}$ à 6,60 .

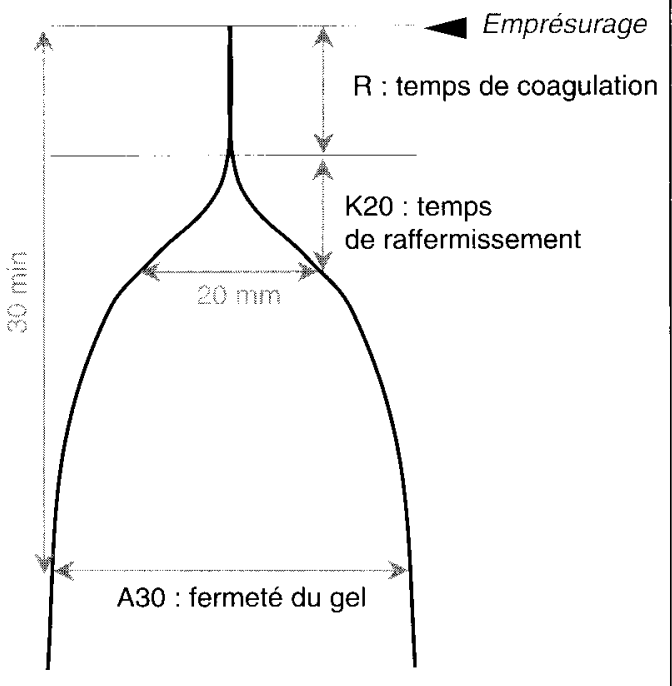


fermissement nécessaire pour obtenir une fermeté de $20 \mathrm{~mm}$ (K20i et K20s) et la fermeté du gel en fin d'analyse (A30i et A30s). Des mesures effectuées sur une poudre de lait reconstituée ont permis de contrôler que la déviation de la méthode au cours du temps était négligeable (quel que soit le paramètre considéré, les écarts extrêmes entre les différentes périodes de mesure ont toujours été inférieurs à $1 \mathrm{~mm}$ ). Au cours de la seconde année, le rendement fromager du lait a été mesuré par centrifugation (Hurtaud et al 1991). La teneur en extrait sec du caillé (ESC), le rendement frais (RF) et le rendement frais corrigé ( par rapport à un caillé de référence de $300 \mathrm{~g} \mathrm{MS} / \mathrm{kg})(\mathrm{RFc})$, calculé d'après les équations proposées par Maubois et Mocquot (1967), ont été déterminés.

\section{3 / Analyse statistique des résultats}

Les animaux de race Tarentaise possédant le variant $C$ de la caséine kappa ( 16 vaches de type $\mathrm{AC}, \mathrm{BC}$ ou $\mathrm{CC}$ ) ont fait l'objet d'un traitement séparé des données : elles ont été regroupées et comparées aux données des vaches Tarentaises présentant un lait de type AA $(n=20)$ ou $A B$ et $B B(n=19)($ cf tableau 3$)$.

L'effet des facteurs expérimentaux a été étudié sur la moyenne des 3 prélèvements hivernaux par analyse de variance. Dans un premier temps, les facteurs introduits dans l'analyse ont été l'année, le lot et la race, ainsi que les interactions année* lot et lot: race. Ces interactions n'ayant jamais été significatives, elles n'ont pas été retenues dans les analyses définitives. Dans un second temps, le facteur variant génétique de la caséine kappa ainsi que l'interaction

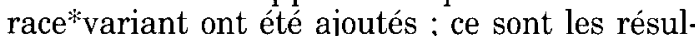
tats de cette analyse qui sont présentés dans le tableau 1. Enfin, une analyse a été réalisée en tenant compte de la covariable taux de caséine.

L'effet du numéro de lactation a été étudié sur les moyennes hivernales et estivales. Pour chacune de ces 2 périodes, les données ont été traitées par analyse de variance. Les facteurs introduits ont été le numéro de lactation et la race des animaux.

\section{2 / Résultats}

\section{1 / Effet des facteurs génétiques}

\section{a / Effet de la race}

Au cours de l'hiver, quand on ne tient pas compte du variant génétique de la caséine kappa dans l'analyse statistique, les taux de matières grasses, de protéines solubles et d'urée n'ont pas été différents d'une race à l'autre. Par contre, les taux de caséine et de calcium ont été supérieurs $(P<0,01)$ chez les Montbéliardes et chez les Tarentaises comparativement aux Pie-Noir (de respectivement 2,1 et $1,4 \mathrm{~g} / \mathrm{l}$ pour les caséines, et 0,05 et $0,08 \mathrm{~g} / \mathrm{l}$ pour le calcium)(figure 1 ).

Le temps de coagulation n'a pas été significativement différent d'une race à l'autre. Par contre, le temps de raffermissement et la fer- meté du gel ont été moins bons $(\mathrm{P}<0,01)$ chez les Pie-Noir que chez les Montbéliardes et les Tarentaises. Les écarts varient entre 10 et $40 \%$ selon les paramètres considérés et les races comparées (figure 1). Ils sont en général plus élevés à $\mathrm{pH}$ standardisé qu'à $\mathrm{pH}$ initial : en effet, le $\mathrm{pH}$ du lait des vaches Pie-Noir est significativement plus faible $(-0,04$ unité, $\mathrm{P}<0,01)$ que celui des Montbéliardes et des Tarentaises. Or, quelle que soit la race, la fermeté du gel et surtout le temps de coagulation sont d'autant meilleurs $(\mathrm{P}<0,01)$ que le $\mathrm{pH}$ du lait est plus faible (respectivement $-0,6 \mathrm{~mm}$ et $+0,3$ min par 0,01 unité $\mathrm{pH}$, en moyenne sur les 3 mesures hivernales). A pH standardisé, le temps de coagulation du lait des vaches PieNoir devient ainsi supérieur $(\mathrm{P}<0,01)$ à celui des Montbéliardes et des Tarentaises. La race des animaux n'a pas eu d'effet significatif sur les rendements frais et corrigé et sur l'extrait sec du caillé.

La plupart des écarts d'aptitude à la coagulation entre races se réduisent, en particulier à $\mathrm{pH}$ initial, lorsque l'on tient compte de la répartition des différents variants de la caséine kappa (tableau 1). Ils ne varient plus alors que de 5 à $27 \%$ selon les paramètres. Le temps de raffermissement et la fermeté du gel à $\mathrm{pH}$ standardisé restent cependant supérieurs $(\mathrm{P}<0,05)$ chez les Montbéliardes et les Tarentaises. Ces différences disparaissent pratiquement lorsque l'on tient aussi compte du taux de caséines du lait.

On n'observe pratiquement pas d'influence significative de la race sur les proportions relatives des différentes caséines. Les vaches Montbéliardes présentent cependant la plus forte proportion de caséines bêta et les Tarentaises la plus faible, en particulier juste après la mise à l'herbe $(47,2$ contre $43,9 \%$, $\mathrm{P}<0,01$ ).

\section{b / Effet du variant de la caséine kappa}

\section{Variants A et B}

Dans les 3 races, les différences de composition chimique du lait observées entre les différents variants de la caséine kappa (taux de caséine supérieur et taux butyreux inférieur avec les laits de type BB) n'ont pas été significatives (tableau 1). Elles conduisent cependant à un écart élevé du rapport TB/TP entre les laits de type $\mathrm{AA}$ et $\mathrm{BB}(1,15$ contre 1,02 , $\mathrm{P}<0,01)$. Les variants de la caséine kappa ont eu un effet important $(\mathrm{P}<0,01)$ sur les paramètres rhéologiques (figure 2 et tableau 1 ). Les laits de type kappa $A B$ ont présenté une aptitude à la coagulation supérieure de 10 à $40 \%$ à ceux des laits de type AA. Les écarts atteignent 20 à $50 \%$ pour les laits de type BB. Le rendement frais a de même été supérieur avec les laits de type $\mathrm{BB}(+19 \%, \mathrm{P}<0,01)$. Cette différence n'existe plus sur le rendement frais corrigé $(-2 \%, \mathrm{P}>0,05)$, en raison d'un extrait sec du caillé supérieur avec les laits de type $\mathrm{AA}(+14 \%, \mathrm{P}<0,01)$. Les caillés de type $\mathrm{BB}$ s'égouttent donc moins bien que les caillés de type AA. L'introduction du taux de caséine en covariable dans l'analyse statistique n'a pratiquement pas modifié ces écarts. 
Figure 1.

Effet de la race sur

l'aptitude à la coagulation du lait (valeurs ajustées pour tenir compte de l'effet du niveau des apports énergétiques).

L'aptitude à la coagulation du lait est meilleure chez les Montbéliardes et les Tarentaises, surtout en raison du taux de caséines plus élevé.
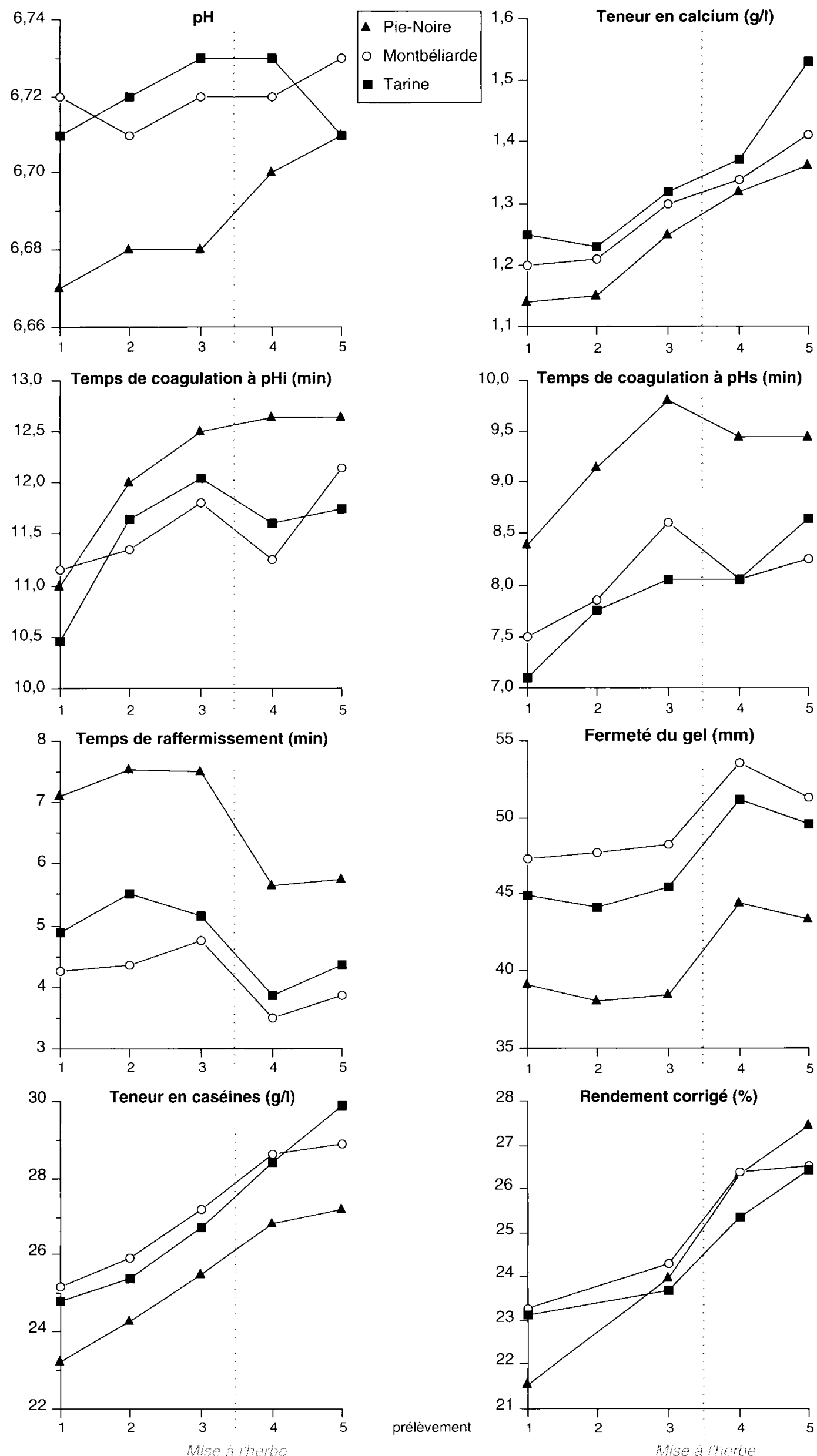

prélèvement
10,07 Temps de coagulation à pHs (min)
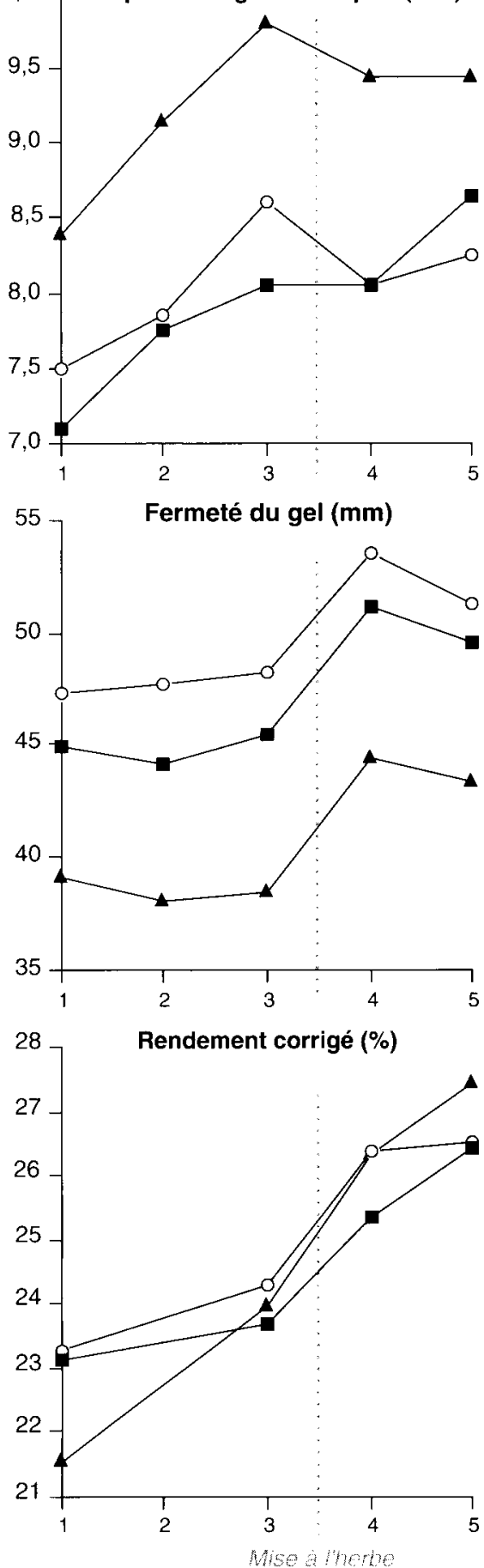
Tableau 1. Composition chimique, caractéristiques rhéologiques et rendements fromagers du lait selon la race, le niveau d'apports énergétiques hivernal et le variant de la caséine kappa (moyenne des trois prélèvements hivernaux).

\begin{tabular}{|c|c|c|c|c|c|c|c|c|c|c|c|c|}
\hline & \multicolumn{3}{|c|}{ Race } & & \multicolumn{2}{|c|}{ Niveau } & & \multicolumn{3}{|c|}{ Caséine kappa } & & \multirow{2}{*}{$\begin{array}{l}\text { ETR } \\
\text { (1) }\end{array}$} \\
\hline & PN & MO & $\mathrm{TA}$ & & B & $\mathrm{H}$ & & AA & $A B$ & $\mathrm{BB}$ & & \\
\hline Effectif & 41 & 42 & 38 & & 59 & 62 & & 56 & 52 & 13 & & \\
\hline Production de lait (kgjj) & 22,3 & 14,4 & 11,5 & **: & 15,2 & 16,9 & * & 16,1 & 16,2 & 16,9 & ns & 3,7 \\
\hline Fourrages $(\mathrm{kg} \mathrm{MS} / \mathrm{j})^{y^{2}}$ & 11,2 & 11,1 & 10,7 & ns & 11,6 & 10,3 & *⿻丷木 & 10,9 & 10,8 & 11,3 & ns & 1,4 \\
\hline Concentrés $\left(\mathrm{kg} \mathrm{MS} / \mathrm{j}^{2 / 21}\right.$ & 7,6 & 4,0 & 3,4 & 恪 & 3,6 & 6,2 & ** & 4,9 & 5,1 & 5,0 & ns & 1,6 \\
\hline Apports énergétiques (UFLjij) & 14,5 & 11,3 & 10,4 & $*$ & 11,5 & 12,6 & 蜳 & 11,9 & 12,0 & 12,3 & ns & 1,6 \\
\hline \multicolumn{13}{|l|}{ Composition du lait } \\
\hline Lactose (gI) & 48,3 & 49,0 & 49,2 & $\mathrm{~ns}$ & 48,6 & 49,0 & ns & 48,5 & 48,4 & 49,7 & $\mathrm{~ns}$ & 1,7 \\
\hline Taux butyreux (gl) & 35,4 & 35,6 & 33,7 & $\mathrm{~ns}$ & 34,5 & 35,3 & $\mathrm{~ns}$ & 36,1 & 35,7 & 33,0 & ns & 4,2 \\
\hline Taux protéique (gl) & 30,6 & 32,9 & 32,2 & $*$ & 31,0 & 32,9 & 綧 & 31,5 & 31,8 & 32,4 & ns & 2,7 \\
\hline Caséines (g/) & 24,6 & 26,5 & 26,1 & $*$ & 25,0 & 26,4 & 悴 & 25,3 & 25,5 & 26,3 & $\mathrm{~ns}$ & 2,3 \\
\hline Protéines solubles (gl) & 6,0 & 6,4 & 6,1 & $\mathrm{~ns}$ & 5,9 & 6,4 & * & 6,2 & 6,2 & 6,1 & $\mathrm{~ns}$ & 0,6 \\
\hline Urée $(g \mid l)$ & 0,34 & 0,33 & 0,31 & $\mathrm{~ns}$ & 0,33 & 0,33 & ns & 0,33 & 0,33 & 0,33 & $\mathrm{~ns}$ & 0,05 \\
\hline Calcium (gf) & 1,18 & 1,24 & 1,26 & $*$ & 1,21 & 1,25 & $*$ & 1,22 & 1,23 & 1,24 & ns & 0,08 \\
\hline $\mathrm{pH}$ & 6,67 & 6,71 & 6,71 & $*$ & 6,71 & 6,69 & ns & 6,70 & 6,71 & 6,69 & ns & 0,05 \\
\hline \multicolumn{13}{|l|}{ Aptitude à la coagulation } \\
\hline \multicolumn{13}{|l|}{ Valeurs à pH initial } \\
\hline - Temps de coagulation (min) & 10,8 & 11,5 & 10,4 & ns & 11,1 & 10,7 & ns & 12,0 & 11,2 & 9,4 & ns & 2,7 \\
\hline - Temps de raffermissement (min) & 7,6 & 6,2 & 7,1 & ns & 8,0 & 5,9 & 誊 & 9,6 & 6,4 & 5,7 & 粎 & 3,2 \\
\hline - Fermeté du gel (mm) & 38,0 & 42,1 & 40,5 & ns & 38,1 & 42,2 & $*$ & 32,6 & 40,5 & 47,5 & 糛 & 8,0 \\
\hline \multicolumn{13}{|l|}{ Valeurs à pH standardisé } \\
\hline - Temps de coagulation (min) & 8,9 & 8,0 & 7,3 & ns & 7,9 & 7,8 & ns & 8,6 & 7,9 & 7,1 & 䊪 & 1,1 \\
\hline - Temps de raffermissement (min) & 5,9 & 4,3 & 4,9 & $*$ & 5,7 & 4,4 & $*$ & 7,1 & 4,4 & 3,7 & $* *$ & 2,0 \\
\hline - Fermeté du gel (mm) & 42,5 & 48,4 & 46,4 & 争 & 44,0 & 47,6 & * & 39,3 & 47,0 & 51,0 & * & 5,5 \\
\hline Extrait sec du caillé $(g / \mathrm{kg})$ & 237 & 233 & 239 & ns & 236 & 237 & ns & 254 & 233 & 222 & $* *$ & 17 \\
\hline Rendement frais $(\%)$ & 31,4 & 33,6 & 31,6 & $\mathrm{~ns}$ & 31,2 & 33,2 & $\mathrm{~ns}$ & 29,2 & 32,7 & 34,7 & 䊏 & 4,8 \\
\hline Rendement corrige ( $(\%)$ & 22,7 & 23,8 & 22,7 & ns & 22,3 & 23,8 & $*$ & 23,2 & 23,1 & 22,8 & $\mathrm{~ns}$ & 2,7 \\
\hline
\end{tabular}

"1' Ecart-type résiduel

${ }^{(2)}$ Moyenne des 3 semaines durant lesquelles ont été réalisés les prélèvements

${ }^{(3)}$ Moyenne des 3 semaines durant lesquelles ont été réalisés les prélèvements. Ces valeurs ont été corrigées pour tenir compte des effets dépressifs du niveau alimentaire et de la part de concentré dans la ration.

ns : non significatif ; * : $\mathrm{P}<0,05 ;{ }^{* *}: \mathrm{P}<0,01$

L'effet des variants de la caséine kappa sur certains paramètres rhéologiques (temps de coagulation et temps de raffermissement) n'a pas été identique dans les 3 races (interaction significative, $\mathrm{P}<0,01)$. Ainsi, les laits des PieNoir de type kappa BB présentent un temps de raffermissement à $\mathrm{pH}$ initial comparable à celui des Montbéliardes et des Tarentaises, alors que celui des laits de Pie-Noir de type AA est près de 2 fois plus important (tableau 2). Cette interaction pourrait être liée à une répartition non homogène entre les races des variants des autres lactoprotéines, en particulier de la bêta-lactoglobuline (dont le variant B est associé dans cet essai comme dans d'autres (Grosclaude 1988) à un temps de coagulation plus élevé). L'examen des caractéristiques rhéologiques du lait des quelques animaux ayant des haplotypes identiques sur cette protéine ne permet cependant pas de confirmer cette hypothèse.
Enfin, le variant de la caséine kappa a une influence importante sur la proportion relative de cette caséine dans les caséines totales : le génotype $\mathrm{BB}$ conduit à une proportion plus importante de caséine kappa que le génotype $\mathrm{AA}(9,5 \%$ contre $6,7 \%, \mathrm{P}<0,01)$ le génotype $\mathrm{AB}$ présentant une proportion intermédiaire $(8,3 \%)$.

Tableau 2. Effets de la race et du variant de la caséine kappa sur l'aptitude du lait à la coagulation (moyenne des 3 prélèvements hivernaux). Tous les animaux comparés recevaient le même niveau d'apports énergétiques (lot $B$ ).

\begin{tabular}{|l|c|c|c|c|c|c|}
\hline Race & \multicolumn{3}{|c|}{ PN } & \multicolumn{3}{c|}{ M0 } \\
\hline Variant de la caséine kappa & $\mathrm{AA}$ & $\mathrm{AB}$ & $\mathrm{BB}$ & $\mathrm{AA}$ & $\mathrm{AB}$ & $\mathrm{BB}$ \\
Effectif & 11 & 7 & 3 & 8 & 8 & 7 \\
Teneur en caséines (gl) & 23,3 & 25,0 & 23,4 & 26,5 & 25,1 & 26,0 \\
Temps de coagulation à pH initial (min) & 9,8 & 8,5 & 7,3 & 8,5 & 7,8 & 7,4 \\
Temps de raffermissement à pH initial (min) & 10,7 & 5,0 & 4,8 & 6,3 & 4,3 & 3,4 \\
\hline
\end{tabular}


Figure 2. Effet du variant génétique de la caséine kappa sur l'aptitude à la coagulation du lait (mesures à $\mathrm{pH}$ standardisé, valeurs ajustées pour tenir compte de la race et du niveau des apports énergétiques).

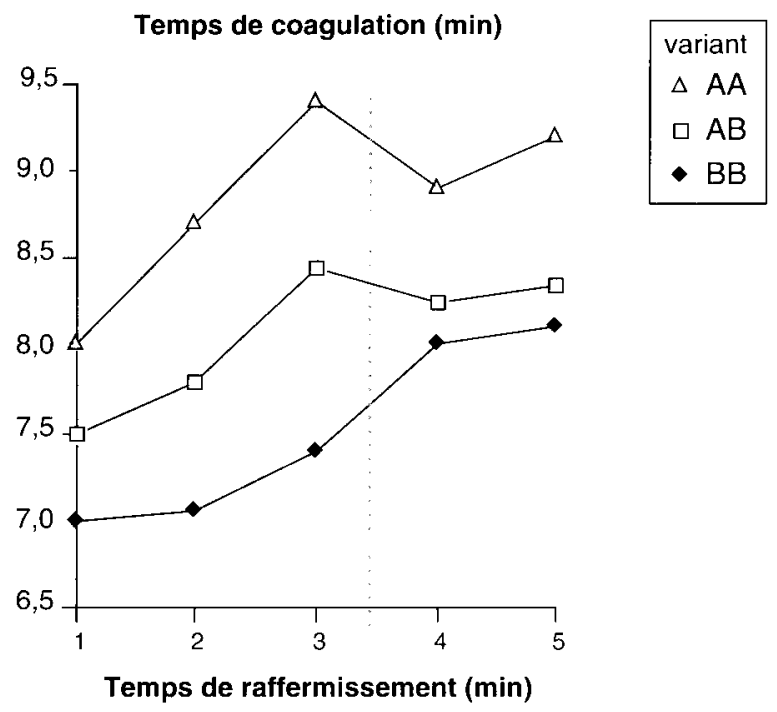

Teneur en caséines $(g / l)$

Le variant B de la caséine kappa a un efffet très favorable sur les paramètres de coagulation.
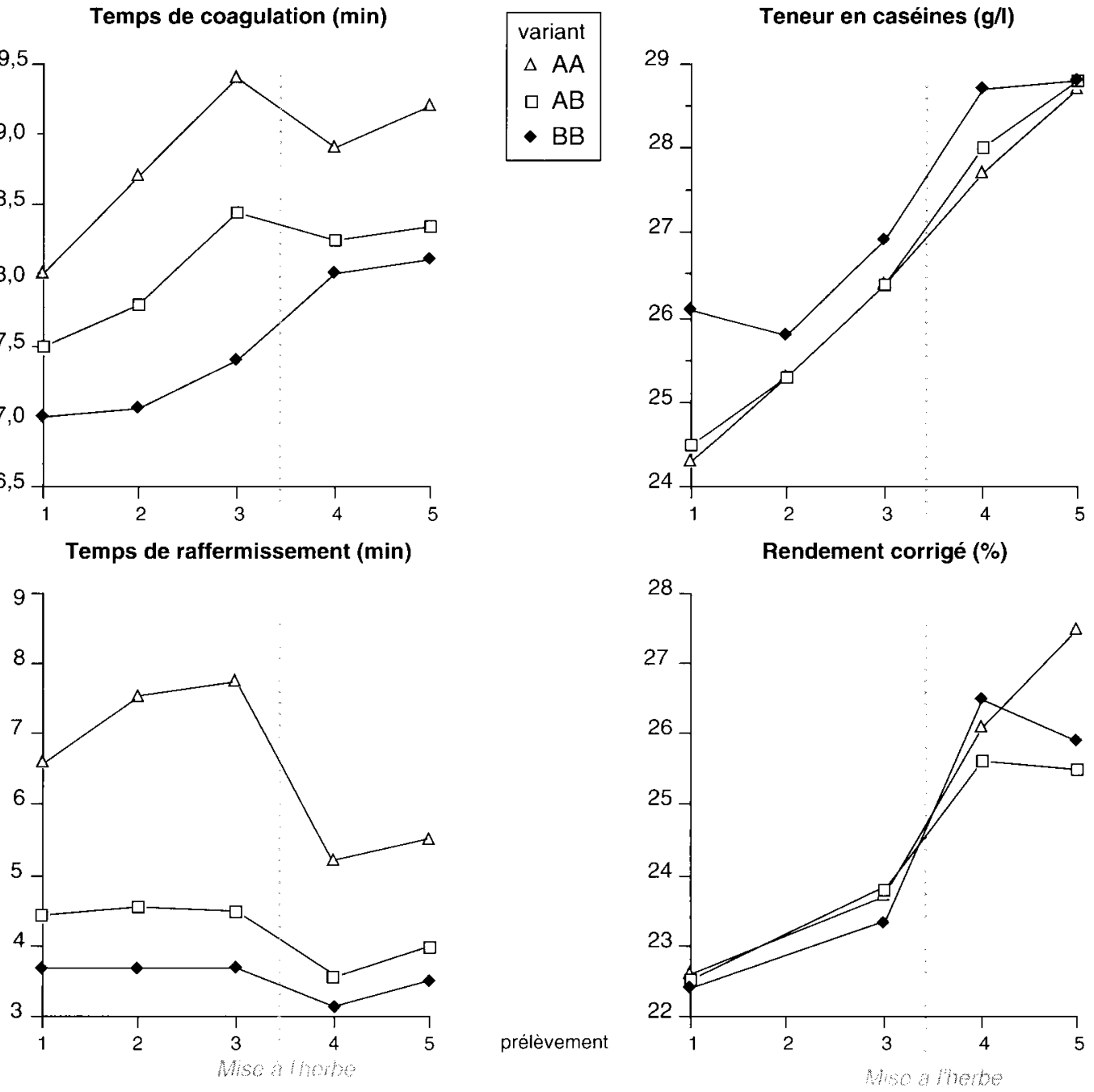

\section{Variant C}

Le lait des 16 vaches Tarentaises possédant le variant kappa $\mathrm{C}$ a présenté des caractéristiques rhéologiques particulières (tableau 3 ). Notamment, le temps de coagulation (à pH initial et à $\mathrm{pH}$ standardisé) a été long, égal ou supérieur à celui du lait des animaux de type kappa AA. Par contre, le temps de raffermissement et la fermeté du gel ont été comparables à ceux mesurés chez les animaux de type kappa $\mathrm{AB}$ ou $\mathrm{BB}$. Les taux de calcium et de caséines ont été voisins de ceux des laits de Tarentaises de type $\mathrm{B}$, de même que le rendement fromager. On a vérifié que ces effets n'étaient pas dus aux variants d'une autre caséine en comparant les animaux possédant le variant kappa $\mathrm{C}$ à ceux possédant le variant kappa $A$ ou $B$ ayant le même génotype pour les caséines bêta et alpha-S.

\section{c / Effet du variant de la bêta- lactoglobuline}

Pour les 3 races, lorsque l'on tient compte de l'effet du variant de la caséine kappa, l'effet de celui de la bêta-lactoglobuline n'est important que sur le taux de protéines solubles du lait $(+10 \%$ pour le type AA comparativement au type $B B, P<0,05)$ et le temps de coagulation (supérieur de respectivement 25 et $15 \%$ à $\mathrm{pH}$ initial et standardisé chez les animaux de type $\mathrm{BB}$ comparativement à ceux de type AA, $\mathrm{P}<0,05$ ).

\section{2 / Effet des facteurs alimentaires}

Les apports énergétiques hivernaux, supérieurs de $1,1 \mathrm{UFL} / \mathrm{j}$ dans le lot $\mathrm{H}$, ont entraîné une augmentation de respectivement $+1,4$ et $+0,5 \mathrm{~g} / \mathrm{l}$ des taux de caséines et de protéines solubles $(\mathrm{P}<0,01)$, et de $0,04 \mathrm{~g} / \mathrm{l}(\mathrm{P}<0,05) \mathrm{du}$ taux de calcium (tableau 1). Parallèlement, excepté le temps de coagulation, les paramètres rhéologiques ont été améliorés de 8 à $26 \%$ $(\mathrm{P}<0,01)$. Le rendement frais corrigé a aussi été supérieur dans les lots $\mathrm{H}(+7 \%, \mathrm{P}<0,05)$. Ces écarts d'aptitude à la coagulation et de rendement disparaissent lorsque l'on tient compte de la teneur en caséines du lait. Seul le temps de raffermissement à $\mathrm{pH}$ initial est encore inférieur dans le lot $\mathrm{H}(-15 \%, \mathrm{P}<0,05)$. 
A la mise à l'herbe (entre les prélèvements 3 et 4), le $\mathrm{pH}$ du lait a augmenté en moyenne de 0,02 unité $(\mathrm{P}<0,01)$, sans détérioration de l'aptitude à la coagulation (figure 3 ). Au contraire, la fermeté du gel et le temps de raffermissement à $\mathrm{pH}$ initial ont été fortement améliorés (de respectivement $12 \%$ et $19 \%, \mathrm{P}<0,01$ ). Simultanément, le rendement frais corrigé a augmenté de $10 \%(\mathrm{P}<0,01)$. Les proportions relatives des différentes caséines ont légèrement varié à la mise à l'herbe : les caséines bêta ont augmenté de 0,9 point $\%$, et les caséines alpha $\mathrm{S}$ diminué de 1,5 point $\%$. La proportion de la caséine kappa n'a pas été affectée.

Ces variations ont été, sauf pour le rendement frais corrigé, beaucoup plus importantes dans les lots B que dans les lots $\mathrm{H}$ (figure 3), en raison de l'augmentation 2 fois moins élevée du taux de caséines à la mise à l'herbe dans ce dernier lot $(+1 \mathrm{~g} / 1$ contre $+2 \mathrm{~g} / \mathrm{l}$, $\mathrm{P}<0,01)$. Ces modifications importantes des paramètres rhéologiques ne se sont pas poursuivies au cours de l'été (prélèvement 5), malgré une augmentation continue du taux de caséines du lait sous l'effet de l'avancement du stade de lactation des animaux.

A la mise à l'herbe, certaines variables ont évolué différemment selon les caractéristiques génétiques des animaux. Le temps de coagulation à $\mathrm{pH}$ standardisé a augmenté chez les Tarentaises $(+9 \%)$ alors qu'il a diminué chez les Pie-Noir et les Montbéliardes (-5\%)(figure 1). De même, la mise à l'herbe a considérablement réduit les écarts d'aptitude à la coagulation observés au cours de l'hiver entre les différents variants de la caséine kappa. Les laits de type kappa $\mathrm{BB}$ n'ont pas présenté d'amélioration, contrairement à ceux de type $\mathrm{AB}$ ou $\mathrm{AA}$. De ce fait, les laits de type $A B$ présentent $a u$ pâturage des caractéristiques très semblables à celles des laits de type $\mathrm{BB}$. Ces observations peuvent être faites sur l'ensemble des paramètres rhéologiques et sont très nettes sur le temps de raffermissement. De même, le rendement frais des laits de type AA est amélioré de façon importante et se rapproche de la valeur mesurée sur les laits de type AB. Il s'accompagne d'une diminution concomitante de l'extrait sec du caillé. Ces modifications se maintiennent au 5ème prélèvement.

\section{3 / Différence entre la première et la deuxième lactation}

La comparaison des valeurs obtenues au cours des 2 hivers ne met en évidence aucune différence entre la première et la seconde lactation des animaux sur les différents critères d'aptitude à la coagulation (tableau 4). La teneur en caséines du lait a cependant été inférieure de $1,4 \mathrm{~g} /(\mathrm{P}<0,05)$ au cours du 2 ème hiver. A l'inverse, au cours de la période estivale, les valeurs de l'ensemble des caractéristiques rhéologiques ont été améliorées en deuxième lactation (de 20 à $30 \%$ selon les paramètres)(tableau 4) bien que les taux de caséines aient été identiques les 2 années. Seul le taux de protéines solubles a été supérieur la seconde année $(+1 \mathrm{~g} / 1, \mathrm{P}<0,01)$.
Tableau 3. Composition chimique et caractéristiques rhéologiques du lait selon le variant de la caséine kappa chez les vaches Tarines (moyenne des 3 prélèvements hivernaux).

\begin{tabular}{|l|ccccc|}
\hline Variant & $\mathbf{A A}$ & $\mathbf{A B}+\mathbf{B B}$ & $\mathbf{A C}+\mathbf{B C}+\mathbf{C C}$ & & ETR $^{1 ! \prime}$ \\
\hline Effectif & 20 & 19 & 16 & & \\
Composition du lait & & & & & \\
Lactose (gfl) & 48,7 & 49,2 & 49,4 & $\mathrm{~ns}$ & 2,0 \\
Taux butyreux (g/) & 34,6 & 34,5 & 36,7 & $\mathrm{~ns}$ & 4,2 \\
Taux protéique (g/) & 31,8 & 31,5 & 33,3 & $\mathrm{~ns}$ & 2,5 \\
Caséines (g/) & 25,4 & 25,4 & 27,2 & $*$ & 2,1 \\
Protéines solubles (g/) & 6,4 & 6,1 & 6,0 & $\mathrm{~ns}$ & 0,5 \\
Urée (g/) & 0,32 & 0,32 & 0,32 & $\mathrm{~ns}$ & 0,04 \\
Calcium (gl) & 1,18 & 1,25 & 1,22 & $\mathrm{~ns}$ & 0,08 \\
pH & 6,72 & 6,72 & 6,69 & $\mathrm{~ns}$ & 0,05 \\
\hline Aptitude à la coagulation & & & & & \\
Valeurs à pH initial & & & & & \\
- Temps de coagulation (min) & 11,3 & 11,2 & 14,1 & $*$ & 3,0 \\
- Temps de raffermissement (min) & 9,1 & 6,9 & 6,3 & $*$ & 3,0 \\
- Fermeté du gel (mm) & 34,1 & 39,4 & 39,0 & $\mathrm{~ns}$ & 8,7 \\
Valeurs à pH standardisé & & & & & \\
- Temps de coagulation (min) & 7,6 & 7,7 & 10,0 & $* *$ & 1,0 \\
- Temps de raffermissement (min) & 6,1 & 4,5 & 4,6 & $*$ & 1,8 \\
- Fermeté du gel (mm) & 41,1 & 46,9 & 48,5 & $* *$ & 5,5 \\
\hline
\end{tabular}

Ecart-type résiduel

ns : non significatif ; $: \mathrm{P}<0,05 ; * *: \mathrm{P}<0,01$

D'une lactation à l'autre, les caractéristiques rhéologiques des laits ont été très répétables (figure 4) : les coefficients de corrélation entre les valeurs des 2 années pour un même animal varient de 0,79 à 0,89 selon les paramètres et la période (hiver ou été), soit des valeurs semblables à celles obtenues pour le taux de caséines. Quelle que soit la période, les taux de calcium du lait ont été significativement plus élevés chez les vaches en deuxième lactation que chez les primipares $(+0,17 \mathrm{~g} / 1$, $\mathrm{P}<0,01$ ).

\section{3 / Discussion}

\section{1 / Influence du polymorphisme génétique}

Les relations entre le polymorphisme génétique des lactoprotéines et la composition et l'aptitude à la coagulation du lait qui ont été observées dans cette étude confirment la plupart des travaux réalisés par ailleurs. En particulier, nous avons observé un effet favorable $\mathrm{du}$ variant $\mathrm{A}$ de la bêta lactoglobuline sur le temps de coagulation et sur la teneur en protéines solubles (Grosclaude 1988), et surtout un effet favorable du variant $B$ de la caséine kappa sur l'ensemble des paramètres rhéologiques mesurés (Schaar 1984, Pagnacco et Caroli 1987, Grosclaude 1988, Rahali et Ménard 1991). Cette amélioration peut provenir en partie d'une augmentation du taux de caséine (Ng-Kwai-Hang et al 1990, Delacroix- 
Figure 3.

Effet du niveau

des apports

énergétiques

sur l'aptitude

à la coagulation du lait (mesures à $p H$ standardisé, valeurs ajustées pour tenir compte de la race et $d u$ variant de la caséine kappa).
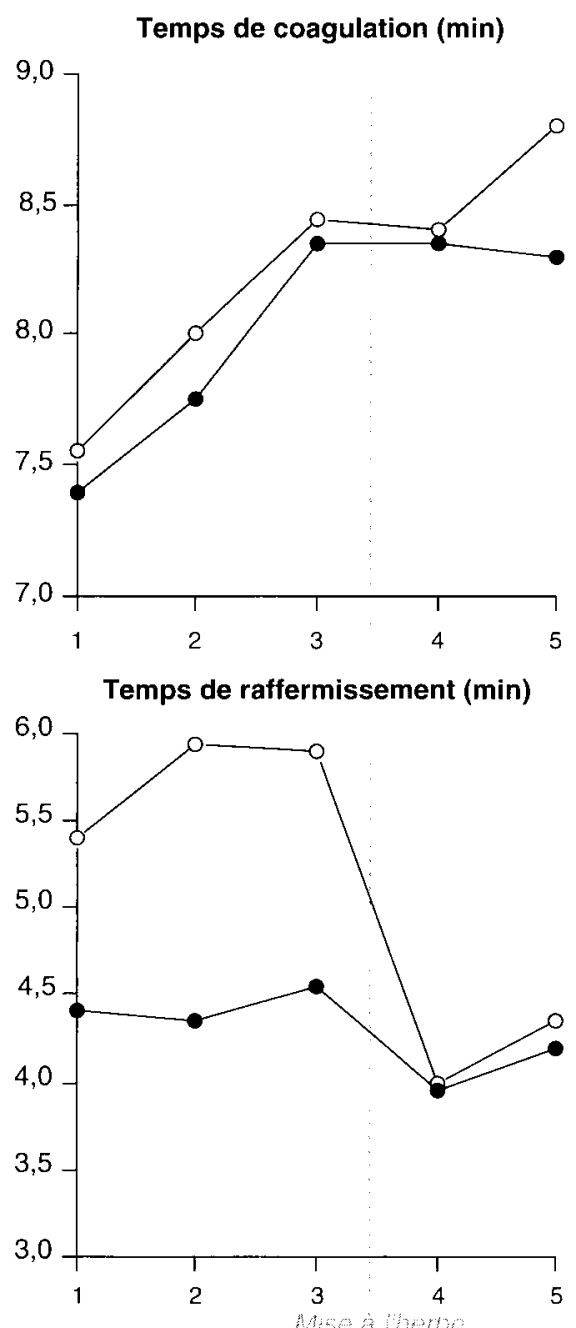

Tableau 4. Variations de la composition chimique du lait et de ses caractéristiques rhéologiques (mesurées à pH initial) entre la première et la deuxième lactation.

\begin{tabular}{|c|c|c|c|c|}
\hline Lactation & 1 & 2 & & ETR $^{(1)}$ \\
\hline Effectif & 20 & 20 & & \\
\hline \multicolumn{5}{|l|}{ Hiver $^{2}$} \\
\hline $\mathrm{pH}$ & 6,70 & 6,71 & ns & 0,05 \\
\hline Caséines (g/) & 25,6 & 24,2 & $*$ & 1,8 \\
\hline Taux butyreux (g/) & 35,8 & 35,7 & ns & 4,0 \\
\hline Protéines solubles (g/) & 5,8 & 6,1 & ns & 0,5 \\
\hline Calcium $(g /)$ & 1,12 & 1,32 & $* *$ & 0,07 \\
\hline Temps de coagulation (min) & 12,1 & 11,6 & ns & 2,5 \\
\hline Temps de raffermissement (min) & 7,6 & 9,0 & ns & 3,9 \\
\hline Fermeté du gel (mm) & 37,3 & 35,0 & ns & 8,8 \\
\hline \multicolumn{5}{|l|}{ Eté $^{-1}$} \\
\hline $\mathrm{pH}$ & 6,71 & 6,73 & ns & 0,05 \\
\hline Caséines (g/) & 28,5 & 28,2 & ns & 2,1 \\
\hline Taux butyreux (g/) & 37,3 & 36,9 & ns & 4,5 \\
\hline Protéines solubles (gl) & 5,7 & 6,6 & $* *$ & 0,7 \\
\hline Calcium (gl) & 1,38 & 1,52 & $* *$ & 0,14 \\
\hline Temps de coagulation (min) & 13,4 & 10,8 & $* *$ & 2,8 \\
\hline Temps de raffermissement (min) & 7,4 & 5,2 & $*$ & 2,6 \\
\hline Fermeté du gel (mm) & 37,7 & 46,1 & $*$ & 9,6 \\
\hline
\end{tabular}

1' Ecart-type résiduel

${ }^{12}$ Moyenne de 3 prélèvements

13. Moyenne de 2 prélèvements

ns : non significatif ; * : $\mathrm{P}<0,05 ; *: \mathrm{P}<0,01$
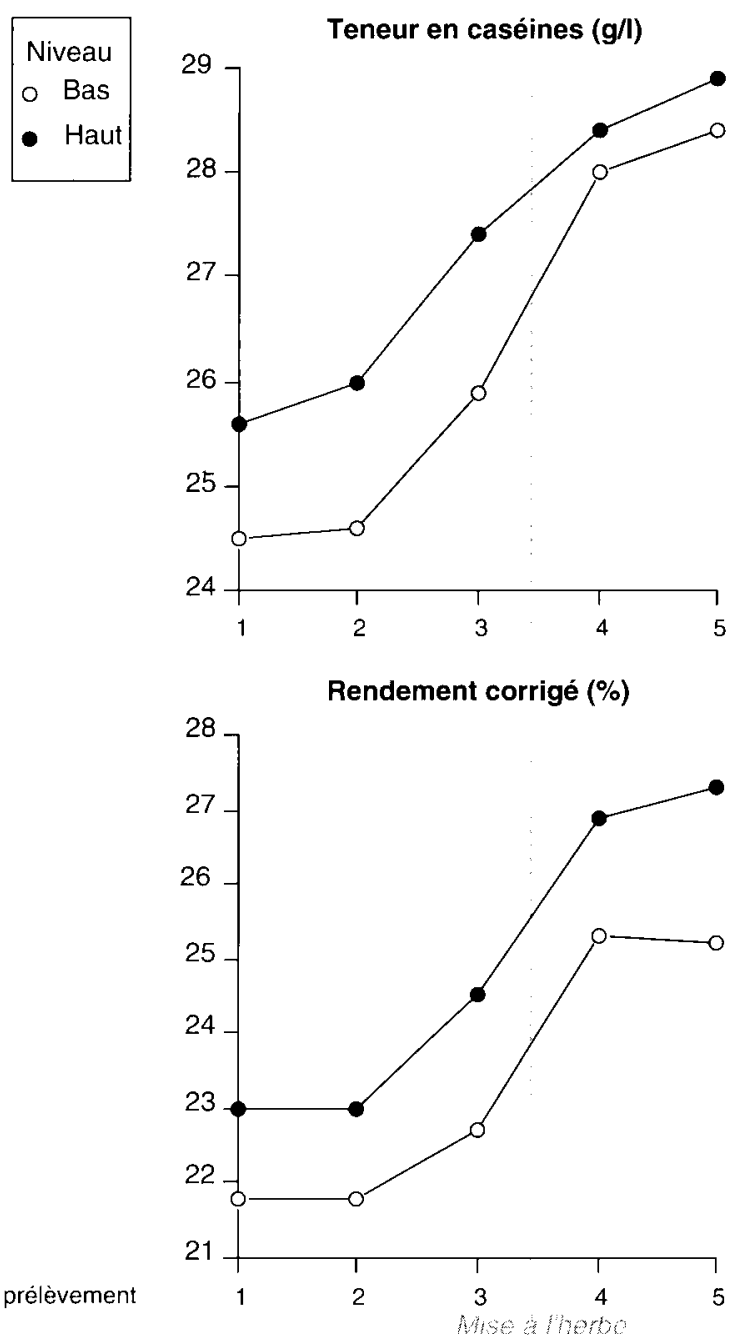

prélèvement

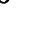

西


Figure 4. Liaisons entre les paramètres de la coagulation du lait d'une lactation à l'autre chez les mêmes vaches.

pH

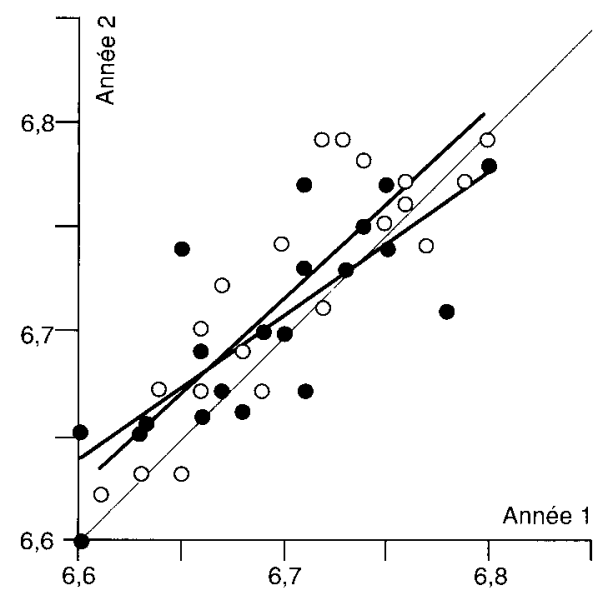

Teneur en caséines (g/l)

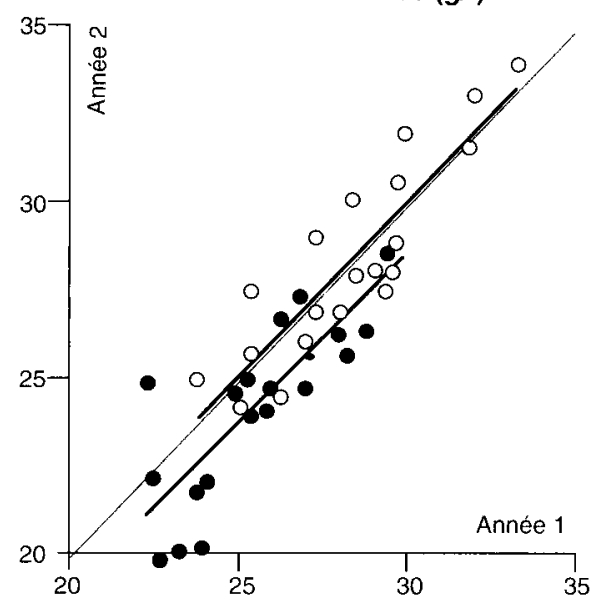

Fermeté du gel à 30 minutes

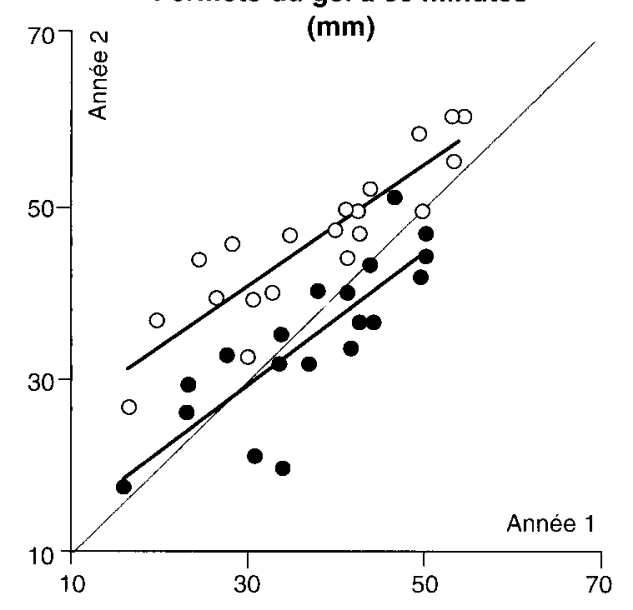

Buchet et al 1993). Nous avons cependant observé qu'à même taux de caséine des écarts importants persistent. Ils pourraient être liés à des micelles plus régulières et d'un diamètre moyen inférieur (Morini et al 1975, DelacroixBuchet et al 1993) fusionnant plus étroitement et donnant une meilleure fermeté au caillé (Niki et Arima 1984, Remeuf et al 1989). Cette amélioration (en particulier celle du temps de coagulation) peut enfin être due, comme nous

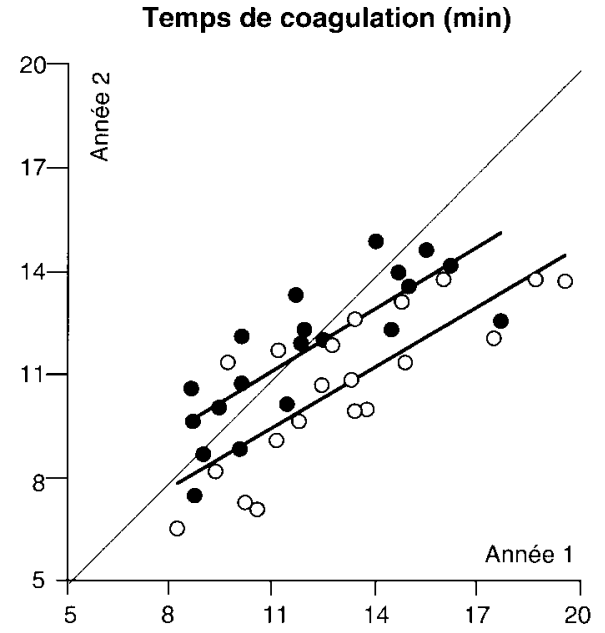

Temps de raffermissement (min)

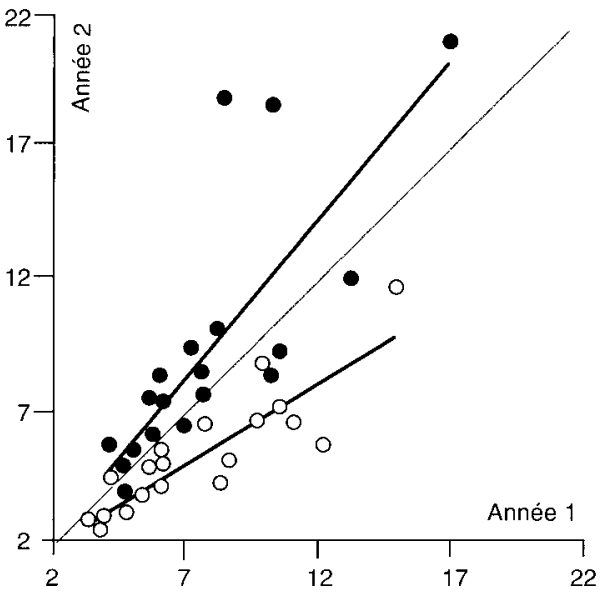

○ Eté

- Hiver l'avons observé, à la proportion de caséine kappa plus importante dans les laits de type B (McLean et al 1984, Delacroix-Buchet et al 1993).

Nous n'avons pas observé d'écart de rendement frais corrigé entre les différents variants de la caséine kappa, contrairement à ce qui est rapporté par la plupart des auteurs ayant mesuré le rendement fromager à partir de 
fabrications (Pagnacco et Caroli 1987, Rahali et Ménard 1991). Le moins bon égouttage que nous avons observé avec les laits de type B est peut-être dû à la méthode d'estimation utilisée (par centrifugation) mais, plus probablement, au rapport $\mathrm{TB} / \mathrm{TP}$ inférieur des laits de type $\mathrm{B}$ comparativement à ceux de type $\mathrm{A}$. La diminution du rapport TB/TP favorise en effet la rétention d'eau dans le caillé. Nous avons cependant confirmé, au cours d'essais de microfabrication de fromage de Saint Nectaire (Macheboeuf et al, non publié), l'absence d'écart de rendement en fromage entre des laits de type kappa $\mathrm{AA}$ et kappa $\mathrm{AB}$, alors que le rendement frais (mesuré au soutirage) était supérieur de 3 à 4 point selon les races avec les laits de type $A B$. Il peut par ailleurs exister des différences selon le mode de fabrication (Schaar et al 1985).

\section{2 / Influence des facteurs alimentaires}

Cette étude a mis en évidence l'effet favorable d'un niveau élevé des apports énergétiques, quels que soient les facteurs génétiques associés, sur l'aptitude à la coagulation du lait et sur le rendement fromager. Comme cela a déja été observé (Storry et al 1983, Remeuf et al 1989, Vertès et al 1989, Garel et Coulon 1990), l'essentiel de cet effet s'explique par l'augmentation de la teneur en protéines du lait quand on augmente le niveau des apports énergétiques (Sutton 1989, Coulon et Rémond 1991). A la mise à l'herbe cependant, il semble que les variations considérables d'aptitude du lait à la coagulation, voisines de celles observées par Grandison et al (1984) et Vertès et al (1989), ne puissent être imputables à la seule variation du taux protéique du lait : alors que l'évolution du taux de caséines a été à peu près linéaire au cours des 5 prélèvements, l'évolution des paramètres rhéologiques présente une amélioration brutale juste après la mise à l'herbe, malgré l'augmentation du $\mathrm{pH}$ du lait. D'autre part, l'augmentation des rendements est identique pour les 2 niveaux d'alimentation hivernaux, malgré une augmentation différente du taux de caséines. Il est donc possible que d'autres facteurs soient en jeu (Vertès et Hoden 1989). La mise à l'herbe entraîne en effet des modifications des teneurs en minéraux du lait (Grandison et al 1984) et de la taille des micelles (Holt et Muir 1978) et peut conduire, comme nous l'avons observé, à une modification significative de la répartition des différentes fractions de caséine. Ces modifications sont dues non seulement à l'augmentation des apports énergétiques à cette période mais peut-être aussi à des variations de la nature des nutriments ingérés : des modifications de nature de la ration ont en effet déjà conduit à des modifications plus ou moins importantes de la composition chimique du lait et de son aptitude à la coagulation (Demarquilly 1963, Grandison et al 1985b, Thomson et al 1985, Vertès et Hoden 1989). Les évolutions différentes d'une race à une autre ou d'un variant de la caséine kappa à un autre, observées à cette période sont révélatrices de la complexité des phénomènes mis en cause. Dans ces 2 cas, c'est d'ailleurs le niveau du facteur le plus favorable au cours de l'hiver qui présente la plus faible variation à la mise à l'herbe.

\section{3 / Effet du numéro de lactation}

Cette étude a mis en évidence une amélioration sensible de l'aptitude à la coagulation du lait entre la première et la deuxième lactation, comme cela est parfois rapporté par les producteurs de fromages fermiers (Martin, communication personnelle) et conformément aux résultats de Schaar (1984), mais contrairement à ceux présentés par Auriol (1961) et Lindström et al (1984). Ces dernières observations ne concernaient cependant que le temps de coagulation et n'avaient pas été réalisées sur les mêmes animaux au cours de lactations successives. Compte tenu des écarts de taux de caséines du lait au cours de l'hiver, certainement liés à une alimentation énergétique légèrement meilleure chez les primipares, cette différence ne s'exprime qu'au cours de l'été où les taux de caséines sont voisins les 2 années. Cet écart ne peut pas être imputé à la méthode de mesure, compte tenu de l'absence de variation des caractéristiques rhéologiques du lait témoin tout au long des 10 séries de mesures effectuées (cf Coulon et Macheboeuf 1993). Par ailleurs, la seconde année, des prélèvements réalisés en même temps sur des vaches en première ou en deuxième lactation conduites dans des conditions comparables, ont confirmé l'existence d'un léger écart des caractéristiques rhéologiques du lait, à même taux de caséines, en faveur des vaches en deuxième lactation (Coulon et Macheboeuf 1993). Les causes de cet écart pourraient être liées à des modifications 1) de la composition des caséines du lait (augmentation de la part de la caséine kappa dont on connaît l'importance dans la phase de coagulation du lait), 2) de la taille des micelles, dont on sait qu'elle peut varier au cours de la lactation (Holt et al 1978) mais aussi d'une lactation à l'autre (Holt et Baird 1978) et 3 ) des équilibres salins du lait (Scharr 1984), en particulier de sa teneur en calcium. Le temps de coagulation du lait est en effet bien lié au rapport $\mathrm{Ca} / \mathrm{azote}$ du lait (Mocquot et al 1954, Auriol 1961) et, dans notre étude, le taux de calcium a été nettement supérieur en deuxième lactation. Cependant, on considère habituellement que ce taux est très peu variable avec l'âge (Guéguen 1971) et il est possible que l'écart observé dans cette étude soit plus dû à un effet année (lié à des facteurs non appréhendés dans cette étude) qu'à un effet propre de l'âge. En effet, la seconde année, des prélèvements réalisés en même temps sur des vaches en première ou deuxième lactation ont conduit à des valeurs identiques chez les 2 types d'animaux (Coulon et Macheboeuf 1993).

\section{Conclusion}

En définitive, cette étude a confirmé l'existence de différences considérables de l'aptitude à la coagulation du lait liées à la race, aux 
variants génétiques des lactoprotéines et aux apports énergétiques alimentaires. Les écarts atteignent, entre des vaches Pie-Noir de type kappa AA alimentées à un bas niveau énergétique et des vaches Montbéliardes de type BB alimentées à un haut niveau, $74 \%$ pour le temps de raffermissement à $\mathrm{pH}$ standardisé. Elle a montré que les différences d'une race à l'autre étaient pratiquement totalement expliquées par les écarts de taux de caséines et la répartition des variants de la caséine kappa. Elle a mis en évidence d'une part un effet spécifique et fugace de la mise à l'herbe sur ces caractérisitiques, et d'autre part des interactions entre les facteurs génétiques entre eux et avec cette période de transition qu'il sera nécessaire de confirmer et d'étudier en détail, y compris sur leurs conséquences sur les caractéristiques des fromages affinés.

\section{Remerciements}

Nous tenons à remercier M.F. Mahé et H. Levéziel qui ont réalisé la caractérisation des variants génétiques des lactoprotéines du lait des animaux de cette étude, ainsi que E. Albaret, M. Javorek et leur équipe pour la réalisation des prélèvements et mesures.

Ce travail a reçu un soutien financier du programme de Recherche-Développement des Alpes du Nord.

Ce texte reprend en partie les résultats originaux publiés par ailleurs par Macheboeuf et al (1993) et Coulon et Macheboeuf (1993)

\section{Références bibliographiques}

Aleandri R., Buttazzoni L.G., Schneider J.C., Caroli A., Davoli R., 1990. The effects of milk protein polymorphisms on milk components and cheeseproducing ability. J. Dairy Sci., 73, 241-255.

Auriol P., 1961. Quelques facteurs de variation du temps de coagulation des laits individuels de vaches. Ann. Biol. Anim. Bioch. Biophy., 1, 152-162.

Brulé G, Lenoir J., 1987. La coagulation du lait. In "Le fromage", A. Eck ed, Lavoisier, pp 1-21.

Coulon J.B., Rémond B., 1991. Réponse de la production et de la composition du lait de vache aux apports nutritifs. INRA Prod. Anim., 4, 49-56.

Coulon J.B., Macheboeuf D., 1993. Note: effet du numéro de lactation sur l'aptitude à la coagulation du lait de vache. Ann. Zootech., à paraitre.

Delacroix-Buchet A., Lefier D., Nuyts-Petit V., 1993. Polymorphisme de la caséine kappa de 3 races bovines françaises et aptitude à la coagulation. Lait, $73,61-72$.

Demarquilly C., 1963. Influence de la nature du pâturage sur la production laitière et la composition du lait. Ann. Zootech., 12, 69-104.

Faverdin P., Hoden A., Coulon J.B., 1987. Recommandations alimentaires pour les vaches laitières. Bull. Tech. CRZV Theix, INRA, 70, 133152.

Garel J.P., Coulon J.B., 1990. Effet de l'alimentation et de la race des vaches sur la fabrication de fromage d'Auvergne de Saint-Nectaire. INRA Prod. Anim., 3, 127-136.

Grandison A.S., Ford G.D., Owen A.J., Millard D., 1984. Chemical composition and coagulating properties of renneted Friesian milk during the transition from winter rations to spring grazing. J. Dairy Res., 51, 69-78.

Grandison A.S., Anderson M., Ford G.D., Newell L., $1985 \mathrm{a}$. Interrelationships between the diet fed to cows, composition and properties of milk and composition and quality of cheshire cheese from farmhouse manufacturers. J. Dairy Res., 52, 587 593.
Grandison A.S., Manning D.J., Thomson D.J., Anderson M., 1985b. Chemical composition, rennet coagulation properties and flavour of milk from cows grazing ryegrass or white clover. J. Dairy Res., 52, 33-39.

Guéguen L., 1971. La composition minérale du lait et son adaptation aux besoins minéraux du jeune. Ann. Nutr. Alim., 25, 335-381.

Grosclaude F., 1988. Le polymorphisme génétique des principales lactoprotéines bovines. Relations avec la quantité, la composition et les aptitudes fromagères du lait. INRA Prod. Anim., 1, 5-17.

Hoden A., Coulon J.B., 1991. Maîtrise de la composition chimique du lait : influence des facteurs nutritionnels sur la quantité et les taux de matières grasses et protéiques. INRA Prod. Anim., 4, 361-367.

Holt C., Baird L., 1978. Natural variations in the average size of bovine caséin micelles. I. Milks from individual Ayrshire cows. J. Dairy Res., 45, 339-345.

Holt C., Muir D., 1978. Natural variations in the average size of bovine caséin micelles. II. Milk samples from creamery bulk silos in south west Scotland. J. Dairy Res., 45, 347-353.

Holt C., Baird L., Muir D.D., 1978. Natural variations in the average size of bovine casein micelles. J. Dairy Res., 45, 339-352.

Hurtaud C., Vérité R., Rulquin H., 1991. Détermination de l'aptitude des laits à la transformation fromagère : intérêts et limites des tests de laboratoires. In "Qualité des laits à la production et aptitude fromagère" (eds M. Journet, A. Hoden et G. Brulé) Rennes.

Laurent F., Coomans D., Gardeur J.N., Vignon B., 1992. Composition azotée et caractéristiques technologiques du lait de vache en relation avec la nature et le niveau d'apport de l'aliment concentré. Lait, 72, 175-183.

Lindström U.B., Antila V., Syvajarvi J., 1984. A note on some genetic and non-genetic factors affecting clotting time of Ayrshire milk. Acta Agric. Scand., $34,349-355$. 
Macheboeuf D., Coulon J.B., D'Hour P., 1993. Effect of breed, protein genetic variants and feeding on cows'milk coagulation properties. J. Dairy Res., 60, 43-54.

Maubois J.L., Mocquot G., 1967. Comment ramener à la même teneur en substance sèche des fabrications de fromages en vue de comparer les rendements respectifs du lait en fromage. Rev. Lait. Franç., 239, 15-18.

Mc Lean D.M., Graham E.R.B., Ponzoni R.W., Mc Kenzie H.A., 1984. Effects of milk protein genetic variants on milk yield and composition. J. Dairy Res., 51, 531-546.

Mc Mahon D.J., Brown R.J., 1982. Evaluation of Formagraph for comparing rennet solutions. J. Dairy Sci., 65, 1639-1642.

Mocquot G., Alais C., Chevalier R., 1954. Etude sur les défauts de coagulation du lait par la présure. Ann. Techn. Agric., 1, 1-44.

Morini D., Losi G., Castagnetti G.B., Benevelli M., Resmini P., Volonterio G., 1975. L'influenza delle varianti genetiche della K-caseina sulla dimensione delle micelle caseiniche. Sci. Tec. Latt. Cas., 26,436444.

Ng-Kwai-Hang K.F., Monardes H.G., Hayes J.F., 1990. Association between genetic polymorphism of milk proteins and production traits during three lactations. J. Dairy Sci, 73, 3414-3420.

Niki R., Arima S., 1984. Effects of size of casein micelle on firmness of rennet curd. Jap. J. Zootech. Sci., 55, 409-415.

Pagnacco G., Caroli A., 1987. Effect of casein and beta-lactoglobulin genotypes on renneting properties of milks. J. Dairy Res., 54, 479-485.

Rahali V., Ménard J.L., 1991. Influence des variants génétiques de la bêta-lactoglobuline et de la kappacaséine sur la composition du lait et son aptitude fromagère. Lait, 71, 275-297.
Remeuf F., Lenoir J., Duby C., 1989. Etude des relations entre les caractéristiques physicochimiques des laits de chèvre et leur aptitude à la coagulation par la présure. Lait, 71, 275-297.

Schaar J., 1984. Effects of kappa-casein genetic variants and lactation number on the renneting properties of individual milks. J. Dairy Res., 51, 397406.

Schaar J., Hansson B., Pettersson H.E., 1985. Effects of genetic variants of kappa-casein an betalactoglobulin on cheesemaking. J. Dairy Res., 52, 429-437.

Storry J.E., Grandison A.S., Millard D., Owen A.J., Ford G.D., 1983. Chemical composition and coagulating properties of renneted milks from different breeds and species of ruminant. J. Dairy Res., 50, 215-229.

Sutton J.D., 1989. Altering milk composition by feeding. J. Dairy Sci., 72, 2801-2814.

Thomson D.J., Beever D.E., Haines M.J., Cammel S.B., Evans R.T., Dhanoa M.S., Austin A.R., 1985. Yield and composition of milk from Friesian cows grazing either perenial ryegrass or white clover in early lactation. J. Dairy Res., 52, 17-31.

Vertès C., 1989. Etude de l'influence de quelques facteurs zootechniques sur la composition physicochimique et l'aptitude fromagère du lait de vache. Thèse Docteur-Ingénieur, ENSA Rennes.

Vertès C., Hoden A., 1989. Qualité fromagère des laits de vache en fonction des régimes à base d'herbe. Lait, 69, 197-209.

Vertès C., Hoden A., Gallard Y., 1989. Effet du niveau d'alimentation sur la composition chimique et la qualité fromagère du lait de vaches Holstein et Normandes. INRA Prod. Anim., 2, 89-96.

\section{Summary}

Effect of breed, protein genetic variants, feeding and age on cows' milk coagulation properties.

One hundred and thirty Holstein (41), Montbéliardes (42) and Tarentaises (54) dairy cows in first or second lactation received during winter one of two levels (high, $\mathrm{H}$; low, $\mathrm{L}$ ) of energy intake, and were later fed identically at pasture. Three times in winter and twice at pasture, individual measurements of milk chemical composition and coagulation properties were performed. Milk from Holstein cows had lower casein and calcium contents, and poorer coagulation properties (curd firming time and curd firmness) than that from Montbéliardes and Tarentaises $(\mathrm{P}<0.01)$. These differences practically disappeared when taking into account the distribution of the different kappacasein variants and milk casein content. kappa-BB milks had coagulation properties 20 to $50 \%$ super- ior, according to characteristic, to those of $\mathrm{AA}$ milks. In the 3 breeds, animals from the $\mathrm{H}$ group had casein contents higher by $1.4 \mathrm{~g} / \mathrm{l}$ than those of the L group, which induced a significant improvement in curd firming time, curd firmness and cheese yield. Turning out to pasture induced an increase of 0.02 unit in milk $\mathrm{pH}$, and improved milk coagulation properties. These changes did not appear to result entirely from the parallel increase in milk casein content. Coagulation properties were poorer in first lactation than in second lactation.

MACHEBOEUF D., COULON J-B., D'HOUR P., 1993. Aptitude à la coagulation du lait de vache. Influence de la race, des variants génétiques des lactoprotéines du lait, de l'alimentation et du numéro de lactation. INRA Prod. Anim., 6 (5), 333-344. 